\title{
Risk Indicators for Air Leaks in Preterm Infants Exposed to Restrictive Use of Endotracheal Intubation
}

\author{
Helmut D. Hummler ${ }^{\mathrm{a}}$ Elisa Parys ${ }^{\mathrm{a}}$ Benjamin Mayer $^{\mathrm{b}}$ Jochen Essers $^{\mathrm{a}}$ \\ Hans Fuchs $^{\mathrm{a}}$ Manuel Schmid ${ }^{\mathrm{a}}$ \\ aDivision of Neonatology and Pediatric Critical Care, Department of Pediatrics, Children's Hospital, and \\ ${ }^{\mathrm{b}}$ Institute of Epidemiology and Medical Biometry, University of UIm, Ulm, Germany
}

\section{Key Words}

Air leaks · Endotracheal intubation · Sustained inflations . Noninvasive ventilation . Prenatal steroids - Epinephrine . Surfactant

\begin{abstract}
Objectives: To identify perinatal risk indicators for air leaks in preterm infants treated with a policy of restrictive use of endotracheal intubation based on sustained inflations followed by noninvasive ventilation in the delivery room. Methods: Perinatal variables and variables of respiratory support in the delivery room were analyzed retrospectively in a cohort of 297 inborn preterm infants with a gestational age $<29$ weeks born in 2005-2009 in a tertiary care center with respect to their associations with air leaks. Multivariate logistic regression analysis was performed to analyze independent risk indicators. Results: Gestational age was 26 weeks + 0 days $(22+3$ to $28+6)$, birth weight was $790 \mathrm{~g}(265-1,660)$ and $270 / 297$ survived (91.0\%). A total of 63 (21.2\%) developed air leaks, 32 (10.8\%) pneumothorax, 44 (14.8\%) pulmonary interstitial emphysema, and $1(0.3 \%)$ pneumopericardium. The infants with air leaks had a higher risk of death $(p<0.01)$ and of intraventricular hemorrhage grade $3 / 4$ $(p<0.05)$. Air leaks were associated with less use of prenatal
\end{abstract}

steroids ( $p<0.01$ ), more frequent use of cardiac compressions $(p<0.01)$, use of a pressure of $30 \mathrm{~cm} \mathrm{H}_{2} \mathrm{O}$ for sustained inflations $(p<0.05)$, and intubation in the delivery room $(p<$ 0.01 ). After multivariate logistic regression only prenatal steroids (OR 0.41, 0.20-0.85), epinephrine (OR 3.56, 1.55-8.15) and surfactant use (OR 12.03, 3.39-42.72) remained significant. Conclusions: Our approach resulted in a high survival rate but was associated with a substantial rate of air leaks, which were associated with death and severe intraventricular hemorrhage. Prenatal steroids were protective, and epinephrine and surfactant use were significant risk indicators, whereas the use of sustained inflations was not a risk factor.

(c) 2015 S. Karger AG, Basel

\section{Introduction}

The occurrence of air leaks such as pneumothorax (PTX) and pulmonary interstitial emphysema (PIE) may result in an acute life-threatening condition in preterm infants and can cause severe intracranial hemorrhage [1]. Air leaks are more common in immature infants with respiratory distress syndrome (RDS) receiving positive pressure ventilation [2] with high peak pressure and/or large tidal volume [3]. Air leaks have been shown to be

\section{KARGER 125}

(c) 2015 S. Karger AG, Base

$1661-7800 / 15 / 1081-0001 \$ 39.50 / 0$

E-Mail karger@karger.com

www.karger.com/neo
Helmut D. Hummler, MD

Division of Neonatology and Pediatric Critical Care

Department of Pediatrics, Children's Hospital, University of Ulm

Eythstrasse 24, DE-89075 Ulm (Germany)

E-Mail helmut.hummler@uni-ulm.de 
associated with a higher rate of bronchopulmonary dysplasia (BPD) [2].

Transition after birth is associated with major physiological changes in respiratory and hemodynamic function [4]. Experimental evidence suggests that sustained inflations could help to recruit lung volume after birth and protect the lungs [5-7] and may decrease the need for mechanical ventilation in preterm infants.

Based on physiological reasoning, sustained inflations were introduced in 1995 as the standard of care in neonates needing respiratory support in the delivery room in our perinatal center, along with early use of nasal continuous positive airway pressure (CPAP) with a high threshold for endotracheal intubation (fraction of inspired oxygen, $\mathrm{FiO}_{2}>0.60$ and positive end-expiratory pressure, $\mathrm{PEEP} \geq 6 \mathrm{~cm} \mathrm{H}_{2} \mathrm{O}$, to reach oxygen saturation, $\left.\mathrm{SpO}_{2}>80 \%\right)$ to avoid invasive mechanical ventilation. This approach was associated with a decrease in the need for mechanical ventilation and the rate of BPD compared to historical controls [8]. Three clinical trials confirmed this finding [9-11], and more recent European guidelines on RDS recognized sustained inflations as a possible alternative approach pending further randomized trials [12].

In the EuroNeoNet 2008 database our perinatal center had a significantly higher incidence of PTX compared to other participating units (11.5\% of all infants with birth weight, $\mathrm{BW} \leq 1,500$ g or gestational age, GA $<32$ weeks, corresponding to the $92 \mathrm{nd}$ percentile within the network - mean rate of PTX: 3.6\%). The objective of this retrospective study was to evaluate risk indicators for air leaks in preterm infants treated with a policy of sustained inflations followed by CPAP and/or noninvasive ventilation in the delivery room as a strategy to avoid intubation and mechanical ventilation.

\section{Methods}

\section{Participants}

We performed a retrospective analysis of data from the charts of infants with GA $<29$ weeks treated from November 1, 2004 to August 31, 2009 at the Perinatal Center, Ulm University. Infants with life-threatening malformations were excluded.

Our approach to stabilize preterm infants in the delivery room included the use of plastic bags to prevent heat loss and brief suctioning of the upper airways to clear fluids before a single nasopharyngeal tube was advanced $3-4 \mathrm{~cm}$ through one nostril. In infants with vigorous respiratory effort, $\mathrm{CPAP}$ with $5 \mathrm{~cm} \mathrm{H}_{2} \mathrm{O}$ using a mechanical ventilator was provided (Stephan F 120; Fritz Stephan Medizintechnik GmbH, Gackenbach, Germany). In infants without vigorous respiratory effort, sustained inflation with $20 \mathrm{~cm} \mathrm{H}_{2} \mathrm{O}$ for $15 \mathrm{~s}$ was applied via the nasopharyngeal tube with the mouth and the other nostril closed manually. The sustained inflation was repeated with a pressure of $25 \mathrm{~cm} \mathrm{H}_{2} \mathrm{O}$ and again with a pressure of $30 \mathrm{~cm} \mathrm{H} \mathrm{H}_{2} \mathrm{O}$ if the heart rate remained $<100 / \mathrm{min}$ and/or if the infant remained cyanotic or $\mathrm{SpO}_{2}$ did not increase, as described in detail elsewhere $[8,9,13]$. CPAP $\left(5 \mathrm{~cm} \mathrm{H}_{2} \mathrm{O}\right)$ was provided between the sustained inflations. This sequence was interrupted depending on the response of the infant, to be followed by CPAP or nasal intermittent mandatory ventilation. At study time an initial $\mathrm{FiO}_{2}$ of 1.0 was used. However, pulse oximetry was used in all infants and weaning from $\mathrm{FiO}_{2}$ was rapidly done to obtain an $\mathrm{SpO}_{2}$ of $80-92 \%$ (Masimo SET; site: right arm). Local guidelines suggested that chest compressions should be given if the heart rate remained $<60$ beats/min despite adequate respiratory support. The initiation of chest compressions may have been rather delayed compared to recommendations by the AHA/AAP guidelines from 2005 [14], as our local guidelines emphasized successful lung aeration rather than chest compressions being critically important for successful stabilization.

Unit guidelines for thresholds for intubation and mechanical ventilation in the delivery room and in the NICU were as follows: (1) $\mathrm{FiO}_{2}>0.60$ to maintain a preductal $\mathrm{SpO}_{2}$ of $>80 \%$ and (2) a $\mathrm{PCO}_{2}$ (partial pressure carbon dioxide) $>65 \mathrm{~mm} \mathrm{Hg}$, or a $\mathrm{PCO}_{2}>60$ $\mathrm{mm} \mathrm{Hg}$ along with clinically significant tachypnea and dyspnea. Nasal ventilation was allowed in the delivery room and thereafter as part of our routine policy (initial settings: $20-25 \mathrm{~cm} \mathrm{H}_{2} \mathrm{O}$, ventilator inspiratory time $0.3 \mathrm{~s}$, ventilator rate $60 / \mathrm{min}$ ). The level of CPAP or PEEP (during nasal ventilation) was later adjusted anywhere between 3 and $8 \mathrm{~cm} \mathrm{H}_{2} \mathrm{O}$ at the discretion of the clinical team, depending on gas exchange and the position of the diaphragm on the chest X-ray.

Unit guidelines for surfactant treatment suggested similar thresholds as for intubation, with the exemption that infants with GA $<25$ weeks received prophylactic intubation and surfactant treatment. Our unit guidelines favored the use of pressure-controlled conventional ventilation, with a PEEP of $4-8 \mathrm{~cm} \mathrm{H}_{2} \mathrm{O}$ depending on $\mathrm{FiO}_{2}$ requirements, a ventilator rate of at least 60 breaths/min, a peak pressure as low as possible to achieve a $\mathrm{PaCO}_{2}$ (partial pressure of arterial carbon dioxide) target of 40-55 mm Hg from the first day of life, with a subsequent increase during the first 14 days for lung protection. High-frequency oscillatory ventilation was used as a rescue mode only. If used, a high lung volume strategy was suggested, starting with mean arterial pressure of $2 \mathrm{~cm}$ $\mathrm{H}_{2} \mathrm{O}$ above that during controlled mechanical ventilation and guided by chest X-rays. Unit guidelines for caffeine treatment suggested to start caffeine in the NICU mainly once weaning from invasive mechanical ventilation was attempted.

\section{Data Collection and Analysis}

Specific variables of prenatal care, perinatal variables, variables on delivery room care, and the use of surfactant were extracted from the patient charts. The use and duration of CPAP and noninvasive mechanical ventilation, survival and the presence of intraventricular hemorrhage (IVH) [15] were recorded. Pulmonary hemorrhage was defined as the presence of blood in tracheal secretions associated with significant respiratory deterioration [16]. $\mathrm{BPD}$ was considered as moderate or severe BPD, as defined elsewhere [17].

All chest X-rays were reviewed by radiologists during the hospital stay. We performed a second review by an experienced neo- 
Table 1. Demographic characteristics of infants with and without air leaks

\begin{tabular}{lccc}
\hline & With air leaks $(\mathrm{n}=63)$ & Without air leaks $(\mathrm{n}=234)$ & $\mathrm{p}$ \\
\hline BW, $\mathrm{g}$ & $740(470-1,410)$ & $808(265-1,660)$ & 0.218 \\
GA, weeks & $25+3(23+1$ to $28+5)$ & $26+2(22+3$ to $28+6)$ & 0.007 \\
Male, $\mathrm{n}$ & $36(57.1 \%)$ & $125(53.4 \%)$ & 0.598 \\
Small for gestational age, $\mathrm{n}$ & $5(7.9 \%)$ & $30(12.8 \%)$ & 0.286 \\
Multiple gestation, $\mathrm{n}$ & $24(38.1 \%)$ & $58(24.8 \%)$ & 0.036 \\
\hline
\end{tabular}

Univariate analysis: values presented are medians (min-max) unless otherwise indicated.

Table 2. Perinatal variables of infants with and without air leaks

\begin{tabular}{lccc}
\hline & $\begin{array}{l}\text { With air leaks } \\
(\mathrm{n}=63)\end{array}$ & $\begin{array}{l}\text { Without air leaks } \\
(\mathrm{n}=234)\end{array}$ & $\mathrm{p}$ \\
\hline Prenatal steroids (any) & $44 / 63(69.8 \%)$ & $199 / 233(85.4 \%)$ & 0.004 \\
Premature rupture of membranes & $27 / 62(43.5 \%)$ & $74 / 234(31.6 \%)$ & 0.078 \\
Cesarean section & $49 / 62(79.0 \%)$ & $179 / 234(76.5 \%)$ & 0.673 \\
Oligohydramnios & $3 / 62(4.8 \%)$ & $9 / 234(3.8 \%)$ & 0.720 \\
Anhydramnios & $9 / 62(14.5 \%)$ & $11 / 234(4.7 \%)$ & 0.006 \\
Vaginal colonization with ureaplasma or chlamydia & $8 / 63(12.7 \%)$ & $21 / 234(9.0 \%)$ & 0.377 \\
\hline
\end{tabular}

Univariate analysis.

natologist (M.S.), who was unaware of other clinical details of these infants. This review was limited to the infants born in 2007-2009 as their X-rays were available electronically, whereas the others were not. Air leak was defined as PTX, PIE, pneumomediastinum, or pneumopericardium.

Statistical analysis of proportions comparing the group of infants with air leaks to the group without air leaks was performed using Fisher's exact test or $\chi^{2}$ tests. Continuous variables were compared using Wilcoxon rank-sum tests. All values presented are medians (min-max). Univariate analysis was performed to analyze risk indicators for air leaks in perinatal, delivery room and NICU care. A multivariate logistic regression analysis was performed to adjust for potential confounders. The numbers of variables included in the model was limited for methodological issues [18], and variables considered for the model as potentially modifiable factors (as selected from the univariate analysis) were GA, the use of prenatal steroids, the use of sustained inflations with $30 \mathrm{~cm}$ $\mathrm{H}_{2} \mathrm{O}$, intubation in the delivery room, and surfactant use.

\section{Results}

During the observational period 302 preterm infants with GA $<29$ weeks were treated at our perinatal center. Of these, 5 infants were excluded from the analysis be- cause of life-threatening malformations (hydrops fetalis and/or lung hypoplasia), leaving 297 infants for the analysis. The median (min-max) BW was $790 \mathrm{~g}(265-1,660)$, GA was 26 weeks +0 days $(22+3$ to $28+6), 161(54.2 \%)$ were male, 35/297 (11.8\%) were small for GA, $82(27.6 \%)$ were multiple gestation, and 228 (77.0\%) were born by cesarean section. Survival to discharge was 270/297 (91\%). A total of $63 / 297(21.2 \%)$ patients developed air leaks, 18 (6.1\%) developed PTX, 30 (10.1\%) developed PIE, 14 (4.7\%) infants developed PTX and PIE, and 1 infant $(0.3 \%)$ developed an isolated pneumopericardium. Air leaks were diagnosed at a median of $16 \mathrm{~h}(0-113)$ after birth. Chest tubes were placed in $26(81.3 \%)$ of the infants with PTX. Table 1 shows the demographic characteristics of the infants with and without air leaks. Infants with air leaks had a lower GA and were more often multiple gestation.

Infants with air leaks were exposed less often to prenatal steroids and more frequently to anhydramnios (table 2). They showed a trend towards a higher rate of premature rupture of membranes, but there was no difference in the rate of cesarean section, the presence of oligohydramnios or a vaginal colonization with ureaplasma or chlamydia. 
Table 3. Variables of delivery room care in infants with and without air leaks

\begin{tabular}{lccc}
\hline & $\begin{array}{l}\text { With air leaks } \\
(\mathrm{n}=63)\end{array}$ & $\begin{array}{l}\text { Without air leaks } \\
(\mathrm{n}=234)\end{array}$ & $\mathrm{p}$ \\
\hline Apgar (5 min) & $8(2-10)$ & $9(1-10)$ & 0.003 \\
Apgar (10 min) & $9(5-10)$ & $9(3-10)$ & 0.015 \\
Cardiac compressions & $9(14.3 \%)$ & $11(4.7 \%)$ & 0.007 \\
Epinephrine & $16 / 62(25.8 \%)$ & $17(7.3 \%)$ & 0.001 \\
Use of sustained inflations & $58 / 63(92.1 \%)$ & $218 / 234(93.2 \%)$ & 0.763 \\
Sustained inflations $(\times 2)$ & $20 / 58(34.5 \%)$ & $105 / 218(48.2 \%)$ & 0.061 \\
Sustained inflations $(\times 3)$ & $31 / 58(53.4 \%)$ & $79 / 218(36.2 \%)$ & 0.024 \\
Sustained inflation $\left(25 \mathrm{~cm} \mathrm{H}_{2} \mathrm{O}\right)$ & $51 / 58(87.9 \%)$ & $178 / 218(81.7 \%)$ & 0.450 \\
Sustained inflation $\left(30 \mathrm{~cm} \mathrm{H} \mathrm{H}_{2} \mathrm{O}\right)$ & $32 / 58(55.2 \%)$ & $80 / 218(36.7 \%)$ & 0.014 \\
Endotracheal intubation & $36(57.1 \%)$ & $82(35.0 \%)$ & 0.003 \\
\hline
\end{tabular}

Univariate analysis: values presented are medians (min-max) unless otherwise indicated.

Table 4. Variables of NICU care in infants with and without air leaks

\begin{tabular}{lccr}
\hline & $\begin{array}{l}\text { With air leaks } \\
(\mathrm{n}=63)\end{array}$ & \multicolumn{1}{c}{$\begin{array}{l}\text { Without air leaks } \\
(\mathrm{n}=234)\end{array}$} & $\mathrm{p}$ \\
\hline Endotracheal intubation (day 1) & $57 / 62(91.9 \%)$ & $137 / 171(80.1 \%)$ & 0.033 \\
Duration of intubation, days & $14(1-161)$ & $6(0-178)$ & $<0.001$ \\
CPAP (any) & $47 / 63(74.6 \%)$ & $223 / 234(95.3 \%)$ & $<0.001$ \\
Duration CPAP/nasal IMV, days & $17(0-108)$ & $20(0-81)$ & 0.068 \\
Surfactant (any) & $60 / 63(95.2 \%)$ & $145 / 234(62.0 \%)$ & $<0.001$ \\
Surfactant (total dose), mg/kg & $218(0-1,111)$ & $110(0-1,321)$ & $<0.001$ \\
Caffeine (any) & $39 / 63(61.9 \%)$ & $196 / 234(83.8 \%)$ & $<0.001$ \\
Time until BW was reached, days & $7(0-19)$ & $10(0-27)$ & 0.007 \\
Time until full feeds, days & $28(8-60)$ & $20(8-200)$ & 0.053 \\
\hline
\end{tabular}

Univariate analysis: values presented are medians ( $\min -\max )$ unless otherwise indicated. IMV = Intermittent mandatory ventilation.

Table 5. Mortality and morbidity in infants with and without air leaks

\begin{tabular}{lccr}
\hline & $\begin{array}{l}\text { With air leaks } \\
(\mathrm{n}=63)\end{array}$ & $\begin{array}{l}\text { Without air leaks } \\
(\mathrm{n}=234)\end{array}$ & $\mathrm{p}$ \\
\hline Death & $18(28.6 \%)$ & $9(3.8 \%)$ & $<0.001$ \\
BPD & $21(35.0 \%)$ & $54(24.1 \%)$ & 0.089 \\
Death or BPD & $39(65.0 \%)$ & $62(27.7 \%)$ & $<0.001$ \\
Pulmonary hemorrhage & $8(12.7 \%)$ & $13(5.6 \%)$ & 0.092 \\
IVH (any grade) & $34(54.0 \%)$ & $75(32.1 \%)$ & 0.001 \\
IVH (grade 3/4) & $16(25.4 \%)$ & $29(12.4 \%)$ & 1.0 \\
PVL (cystic) & $1(1.6 \%)$ & $3(1.3 \%)$ & 0.901 \\
Retinopathy of prematurity & $18(28.6 \%)$ & $65(27.8 \%)$ & 1.0 \\
Necrotizing enterocolitis (Bell stage 2 or 3) & $4(6.3 \%)$ & $16(6.8 \%)$ & 0.763 \\
Persistent ductus arteriosus & $35(55.6 \%)$ & $125(53.4 \%)$ & 0.044 \\
Early-onset sepsis (positive blood culture) & $2(3.2 \%)$ & 0 & 0.377 \\
CRP $>$ 20 mg/l during days 1-3 & $8(12.7 \%)$ & $21(9.0 \%)$ & \\
\hline
\end{tabular}


Table 6. Risk indicators for air leaks

\begin{tabular}{lcll}
\hline & OR & $95 \% \mathrm{CI}$ & $\mathrm{p}$ \\
\hline Prenatal steroids & 0.41 & $0.20-0.85$ & 0.02 \\
GA (per week) & 0.87 & $0.70-1.06$ & 0.17 \\
Epinephrine use in delivery room & 3.56 & $1.55-8.15$ & 0.003 \\
Surfactant use & 12.03 & $3.39-42.72$ & 0.001 \\
Intubation in delivery room & 0.66 & $0.31-1.38$ & 0.27 \\
Sustained inflation $\left(30 \mathrm{~cm} \mathrm{H}_{2} \mathrm{O}\right)$ & 1.53 & $0.79-2.97$ & 0.21 \\
\hline
\end{tabular}

Multivariate logistic regression analysis.

Infants with air leaks had lower Apgar scores, received cardiac compressions and epinephrine more often in the delivery room and underwent endotracheal intubation more frequently (table 3 ), suggesting that they were sicker at birth. There was no difference in the use of sustained inflations between both groups, but there was a trend towards the use of more than one sustained inflation in those who developed air leaks. Three sustained inflations and a pressure of $30 \mathrm{~cm} \mathrm{H}_{2} \mathrm{O}$ were used significantly more often in those infants who developed air leaks. Endotracheal intubation at any time, the duration of invasive mechanical ventilation and the use of surfactant were significantly associated with the development of air leaks (table 4). In infants with air leaks, CPAP and caffeine was used less frequently, and BW was regained earlier.

Infants with air leaks had a higher rate of death, death or BPD, IVH, IVH grade 3/4, and early-onset sepsis with a positive blood culture (table 5). There was a trend towards a higher rate of BPD and pulmonary hemorrhage, but there was no difference in the rate of retinopathy of prematurity and persistent ductus arteriosus.

Besides GA, we considered indicators with statistically significant differences from the univariate analyses for the regression analysis, which may be influenced by different approaches in perinatal, delivery room and NICU care. Variables considered for the model were GA, the use of prenatal steroids, use of epinephrine, surfactant use, intubation, and the use of sustained inflation with a pressure of $30 \mathrm{~cm} \mathrm{H}_{2} \mathrm{O}$ in the delivery room (table 6). There was a significantly lower risk of air leaks with the use of prenatal steroids and a significantly higher risk with the use of epinephrine for resuscitation and when surfactant was used in the delivery room. Intubation in the delivery room did not show an association with air leaks, and the use of a pressure of $30 \mathrm{~cm} \mathrm{H}_{2} \mathrm{O}$ for sustained inflations was no longer significant.

Air Leaks in Preterm Infants

\section{Discussion}

Air leaks were associated with an increased risk of mortality and severe IVH, as shown before in a case-control study [19]. Interpretation of risk indicators is limited by the retrospective design of our study, and any significant association may suggest more severe lung disease in infants with air leaks and not necessarily imply a causal relationship. However, antenatal corticosteroids clearly decrease the incidence of RDS and protect against air leaks [20]. Our rate for (any) prenatal steroids was close to average in the EuroNeoNet (2008: 73\%; 2009: 82\%). There is biological plausibility for a causal relationship of a higher risk of air leaks in infants with a lower GA and in multiple gestation pregnancies, which may be related to lower maturity and to the higher incidence of RDS, which has been shown after adjustment for GA [21]. Epinephrine use in the delivery room may be an indicator of dramatic situations where caretakers may overinflate lungs inadvertently. Anhydramnios may result in impaired lung development and airway collapse - described as dry lung syndrome $[22,23]$.

Infants with air leaks were intubated more often, remained longer on invasive mechanical ventilation, received surfactant more frequently, and reached the initial BW earlier, which is probably related more to a positive fluid balance rather than a true gain in body mass. The lower rate of caffeine in infants with air leaks may be explained by our guidelines of caffeine use and missing the opportunity for weaning because of the poor respiratory condition in many of these infants, as well as their higher mortality rate secondary to cardio-respiratory failure. The higher rate of death, death or BPD and IVH in infants with air leaks may be explained by severe lung injury and marked changes in hemodynamics associated with air leaks $[1,24,25]$.

Whereas intubation in the delivery room did not remain a significant risk indicator after adjusting for other confounders in the logistic regression analysis, the observed relationship between the use of surfactant and air leaks remained significant. Our strategy to avoid endotracheal intubation may have resulted in delayed delivery of surfactant [26]. Although early randomized trials on prophylactic compared to selective (and thus delayed) use of surfactant demonstrated a decreased risk of air leaks and mortality, a more recent Cochrane review on large trials with a more widespread use of prenatal steroids and early CPAP no longer support these differences [27]. However, in one large randomized trial the routine use of CPAP with selective surfactant use in spontaneously

Neonatology 2015;108:1-7 DOI: $10.1159 / 000375361$ 
breathing preterm infants with a GA of 25-28 weeks demonstrated a higher incidence of PTX, but survival without BPD was similar [28]. The use of surfactant may be just a marker for more severe lung disease in our group of infants with air leaks, leading to the observed association without any causal relationship.

The association of air leaks with the use of sustained inflations with a pressure of $30 \mathrm{~cm} \mathrm{H}_{2} \mathrm{O}$ was no longer significant after adjustment for GA and other cofactors in the multivariate regression analysis. One possible interpretation of this data could be the absence of a causal relationship. Another possible explanation is that more immature infants have a higher risk of air leaks when exposed to sustained inflations. Five sustained inflations with a duration of $5 \mathrm{~s}$ using a tidal volume of 8,16 and 32 $\mathrm{ml} / \mathrm{kg}$ affected lung compliance and impaired response to surfactant in preterm lambs, suggesting lung damage secondary to overdistension [29]. The use of sustained inflations with a tidal volume of $16 \mathrm{ml} / \mathrm{kg}$ resulted in impaired lung mechanics when applied immediately after birth [30]. Interestingly, similar inflations given 10 or $60 \mathrm{~min}$ after birth resulted in a much lower airway pressure and had no negative effect on lung compliance [30]. These observations suggest that immediately after birth gas inflations compete with residual lung fluid, resulting in local overdistension as tidal volume may not be evenly distributed throughout the lungs immediately after birth [31]. Two randomized controlled trials using sustained inflations as the primary mode of respiratory support immediately after birth have been reported, and neither showed an increased rate of air leaks in premature infants exposed to sustained inflations $[9,10]$; however, neither of the studies included infants with a GA $<25$ weeks.

Our rate of PTX in 2008 (11.5\% of all infants with BW $\leq 1,500$ g or GA $<32$ weeks) was higher than the rate of $9.2 \%$ in a cohort of preterm infants with a GA of 23-28 weeks exposed to CPAP after birth [19] and was the driv- ing force to perform this analysis. After this data became available, we changed our noninvasive respiratory approach slightly, and we have lowered our threshold for surfactant therapy to an $\mathrm{FiO}_{2}$ of 0.40 and limited the peak inflating pressure of sustained inflations to $25 \mathrm{~cm} \mathrm{H}_{2} \mathrm{O}$. Although we observed a lower rate of PTX (2010: 2.1\%; 2011: $2.3 \%$ - corresponding to the 38th and 28th percentiles in the EuroNeoNet), we can only speculate whether there is a causal relationship between policy changes and decreasing PTX rates.

Our study has certain limitations. First, because of the retrospective design any association detected certainly does not prove any causal relationship. Second, for logistic reasons, only X-rays of those infants born in 20072009 could be double-checked by a neonatologist. Third, interventions during care in the NICU such as volumetargeted ventilation may influence the rate of PTX and/or PIE $[32,33]$ but were not assessed in this retrospective analysis as we were particularly interested in studying indicators of antenatal and delivery room care potentially associated with air leaks.

We conclude that our policy of using sustained inflations to stabilize respiration followed by noninvasive ventilation in the delivery room to avoid endotracheal intubation resulted in a high survival rate but was not able to reduce the occurrence of severe adverse outcomes related to the severity of cardiac and respiratory failure immediately after birth. Prenatal steroids were protective, and epinephrine and surfactant use were significant independent risk indicators, whereas the use of sustained inflations was not. Randomized trials are necessary to test different pressures for sustained inflations and to prove whether sustained inflations followed by noninvasive ventilation are more beneficial in stabilizing functional residual capacity and gas exchange and whether they improve short- and long-term outcomes without relevant side effects.

\section{References}

1 Hill A, Perlman JM, Volpe JJ: Relationship of pneumothorax to occurrence of intraventricular hemorrhage in the premature newborn. Pediatrics 1982;69:144-149.

2 Aly H, Massaro A, Acun C, Ozen M: Pneumothorax in the newborn: clinical presentation, risk factors and outcomes. J Matern Fetal Neonatal Med 2014;27:402-406.

3 Monin P, Vert P: Pneumothorax. Clin Perinatol 1978;5:335-350.
4 van Vonderen JJ, Roest AAW, Siew ML, Walther FJ, Hooper SB, te Pas AB: Measuring physiological changes during the transition to life after birth. Neonatology 2014;105:230242.

5 Pas te $A B$, Siew M, Wallace MJ, Kitchen MJ, Fouras A, Lewis RA, et al: Effect of sustained inflation length on establishing functional residual capacity at birth in ventilated premature rabbits. Pediatr Res 2009;66:295-300.
6 Tingay DG, Bhatia R, Schmölzer GM, Wallace MJ, Zahra VA, Davis PG: Effect of sustained inflation vs. stepwise PEEP strategy at birth on gas exchange and lung mechanics in preterm lambs. Pediatr Res 2014;75:288-294.

7 Polglase GR, Tingay DG, Bhatia R, Berry CA, Kopotic RJ, Kopotic CP, et al: Pressure- versus volume-limited sustained inflations at resuscitation of premature newborn lambs. BMC Pediatr 2014; 14:43. 
8 Lindner W, Vossbeck S, Hummler H, Pohlandt F: Delivery room management of extremely low birth weight infants: spontaneous breathing or intubation? Pediatrics 1999;103: 961-967.

9 Lindner W, Högel J, Pohlandt F: Sustained pressure-controlled inflation or intermittent mandatory ventilation in preterm infants in the delivery room? A randomized, controlled trial on initial respiratory support via nasopharyngeal tube. Acta Paediatr 2005;94:303309.

10 Pas te $\mathrm{AB}$, Walther FJ: A randomized, controlled trial of delivery-room respiratory management in very preterm infants. Pediatrics 2007;120:322-329.

11 Lista G, Fontana P, Castoldi F, Cavigioli F, Dani C: Does sustained lung inflation at birth improve outcome of preterm infants at risk for respiratory distress syndrome? Neonatology 2011;99:45-50.

12 Sweet DG, Carnielli V, Greisen G, Hallman M, Ozek E, Plavka R, et al: European consensus guidelines on the management of neonatal respiratory distress syndrome in preterm infants - 2013 update. Neonatology 2013;103: 353-368.

13 Lindner W, Pohlandt F: Oxygenation and ventilation in spontaneously breathing very preterm infants with nasopharyngeal CPAP in the delivery room. Acta Paediatr 2007;96: $17-22$.

14 American Heart Association, American Academy of Pediatrics: 2005 American Heart Association (AHA) guidelines for cardiopulmonary resuscitation (CPR) and emergency cardiovascular care (ECC) of pediatric and neonatal patients: neonatal resuscitation guidelines. Pediatrics 2006;117:e1029-e1038.

15 Papile LA, Burstein J, Burstein R, Koffler H: Incidence and evolution of subependymal and intraventricular hemorrhage: a study of infants with birth weights less than 1,500 gm. J Pediatr 1978;92:529-534.

16 Kluckow M, Evans N: Ductal shunting, high pulmonary blood flow, and pulmonary hemorrhage. J Pediatr 2000;137:68-72.

17 Jobe AH, Bancalari E: Bronchopulmonary dysplasia. Am J Respir Crit Care Med 2001; 163:1723-1729.

18 Harrell FE, Lee KL, Mark DB: Multivariable prognostic models: issues in developing models, evaluating assumptions and adequacy, and measuring and reducing errors. Stat Med 1996; 15:361-387.

19 Bhatia R, Davis PG, Doyle LW, Wong C, Morley CJ: Identification of pneumothorax in very preterm infants. J Pediatr 2011;159:115120.e1.

20 Roberts D, Dalziel S: Antenatal corticosteroids for accelerating fetal lung maturation for women at risk of preterm birth. Cochrane Database Syst Rev 2006;3:CD004454.

21 Qiu X, Lee SK, Tan K, Piedboeuf B, Canning R; Canadian Neonatal Network: Comparison of singleton and multiple-birth outcomes of infants born at or before 32 weeks of gestation. Obstet Gynecol 2008;111:365-371.

22 McIntosh N: Dry lung syndrome after oligohydramnios. Arch Dis Child 1988;63:190193.

23 Losa M, Kind C: Dry lung syndrome: complete airway collapse mimicking pulmonary hypoplasia? Eur J Pediatr 1998;157:935-938.

24 Dykes FD, Lazzara A, Ahmann P, Blumenstein B, Schwartz J, Brann AW: Intraventricular hemorrhage: a prospective evaluation of etiopathogenesis. Pediatrics 1980;66:42-49.

25 Lipscomb AP, Thorburn RJ, Reynolds EO, Stewart AL, Blackwell RJ, Cusick G, et al: Pneumothorax and cerebral haemorrhage in preterm infants. Lancet 1981;1:414-416.
26 Fuchs H, Lindner W, Leiprecht A, Mendler MR, Hummler HD: Predictors of early nasal CPAP failure and effects of various intubation criteria on the rate of mechanical ventilation in preterm infants of. Arch Dis Child Fetal Neonatal Ed 2011;96:F343-F347.

27 Rojas-Reyes MX, Morley CJ, Soll R: Prophylactic versus selective use of surfactant in preventing morbidity and mortality in preterm infants. Cochrane Database Syst Rev 2012; 3:CD000510.

28 Morley CJ, Davis PG, Doyle LW, Brion LP, Hascoet J-M, Carlin JB, et al: Nasal CPAP or intubation at birth for very preterm infants. $\mathrm{N}$ Engl J Med 2008;358:700-708.

29 Björklund LJ, Ingimarsson J, Curstedt $\mathrm{T}$, Larsson A, Robertson B, Werner O: Lung recruitment at birth does not improve lung function in immature lambs receiving surfactant. Acta Anaesthesiol Scand 2001;45:986993.

30 Ingimarsson $\mathrm{J}$, Björklund $\mathrm{LJ}$, Curstedt $\mathrm{T}$, Gudmundsson S, Larsson A, Robertson B, et al: Incomplete protection by prophylactic surfactant against the adverse effects of large lung inflations at birth in immature lambs. Intensive Care Med 2004;30:1446-1453.

31 Jobe AH, Hillman N, Polglase G, Kramer BW, Kallapur S, Pillow J: Injury and inflammation from resuscitation of the preterm infant. Neonatology 2008;94:190-196.

32 Wheeler KI, Klingenberg C, Morley CJ, Davis PG: Volume-targeted versus pressure-limited ventilation for preterm infants: a systematic review and meta-analysis. Neonatology 2011; 100:219-227.

33 Vellanki H, Antunes M, Locke RG, McGreevy T, Mackley A, Eubanks JJ, et al: Decreased incidence of pneumothorax in VLBW infants after increased monitoring of tidal volumes. Pediatrics 2012;130:e1352-e1358. 